\title{
Gain-scheduled Adaptive Observer for Induction Motors: An LMI Approach
}

\author{
Fethi Farhani $^{1}$, Abderrahmen Zaafouri ${ }^{2}$, Abdelkader Chaari ${ }^{3}$ \\ University of Tunis, Unit C3S, Higher School of Sciences and Techniques of \\ Tunis (ESSTT), 5 Av. Taha Hussein, BP 56, 1008 Tunis, Tunisia; \\ ${ }^{1}$ E-mail: fethi.farhani@issatkr.rnu.tn \\ ${ }^{2}$ E-mail: abderrahmen.zaafouri@isetr.rnu.tn \\ ${ }^{3}$ E-mail: assil.chaari@esstt.rnu.tn
}

\begin{abstract}
This paper presents a new adaptive rotor flux observer with both speed and rotor and stator resistance identification. The proposed solution, which is based on a full-order Luenberger observer, guarantees a perfect reconstruction of state variables while reducing the drive system complexity. By using the Lyapunov's direct method, the gain-scheduled of the suggested observer can be achieved by solving four bilinear matrix inequalities using the LMI Toolbox of MATLAB. To overcome the problem of parametric variation of induction machine, a tracking-parameter mechanism is used. To validate the effectiveness and robustness of the proposed solution, some simulation results are provided.
\end{abstract}

Keywords: Asymptotic stability; Gain-scheduled; linear matrix inequalities; Pole Placement; State estimation

\section{Introduction}

The three-phase squirrel-cage induction machine driven by static converters is the most used in high-performance industrial applications. It currently occupies an important place in rotating electrical machines market thanks to its robustness, simplicity, low-cost manufacturing and high specific power.

Nowadays, as a consequence of the important progress realized in the technology of microcontrollers and electronic power switches, it is possible to realize variable speed drives using vector control based on complex algorithms while taking into account the difficulties related to the nonlinearities of the induction machine. The vector control introduced by Blaschke [1] has improved the performances of the induction machine so that it provided performances similar to the DC machine. In the literature, there are two main techniques of field-oriented control: direct and indirect orientation [2]-[5]. Both techniques require an online recognition of the state variables. This involves finding software solutions to reconstruct the 
immeasurable variables such as rotor or stator flux and even measurable variables such as rotation speed to improve the reliability and robustness of the control schemas.

In the literature, several solutions based on the model of induction machines provide an estimate of the flux vector [6]-[8].These techniques are highly sensitive to parametric variations [9]. This imposes the search for methods to reduce the influence of these disturbances on the stability and efficiency of both state estimation and control algorithm of induction machines. In this context we propose a solution derived from the theory of Lyapunov which ensures the online adaptation of the rotor and stator resistances of the induction machine.

Direct measurement of mechanical speed by using an optical tachometer or a shaft-mounted encoder greatly increases the cost and reduces the reliability. However, even if a speed sensor is used, we can envisage a control strategy capable of tolerating sensor failure. In the last two decades, several techniques have been employed for speed sensor emulation. Rotor speed estimation techniques can be mainly classified into three methods; the first technique is based on the injection of high frequency signals to track the mechanical speed [10], [11]. The second technique is based on Kalman filter for rotor speed tracking [12]. The third technique is based on adaptive mechanisms hence its name [13].

The present article is organized as follows: In section 2, the model of induction motor will be defined. Section 3 is devoted to developing the adaptive full-order observer on the one hand and to present online parameters and speed tracking mechanisms on the other. Improving performance and robustness of the proposed observer is established in section 4 . In section 5 we present the online procedure for efficiency optimization of induction motor. The validation of the proposed solution as well as the discussion of the results are carried out in section 6. Finally, a conclusion will be provided.

\section{Induction Machine Modeling}

The dynamics of the induction machine is defined by the following equation

$$
\left\{\begin{array}{l}
\dot{x}=\left(A+\omega_{r} A_{\omega}\right) x+B v_{s} \\
i_{s}=C x
\end{array}\right.
$$

The time derivative of stator flux in a stationary reference frame is given as follows

$$
\dot{\lambda}_{s}=v_{s}-R_{s} i_{s}
$$


We deduce the rotor flux expressions (3) as a function of the stator flux and current

$$
\lambda_{r}=D\left[\lambda_{s} i_{s}\right]^{T}=C_{1} x
$$

In the equations (1), (2) and (3), the following symbols are used:

$$
\begin{aligned}
& x=\left[\begin{array}{ll}
i_{s} & \lambda_{r}
\end{array}\right]^{T} ; A=\left[\begin{array}{ll}
A_{11} & A_{12} \\
A_{21} & A_{22}
\end{array}\right] ; A_{\omega}=\left[\begin{array}{ll}
0_{2 x 2} & A_{\omega 1} \\
0_{2 x 2} & A_{\omega 2}
\end{array}\right] ; B=\left[\begin{array}{ll}
B_{1} & 0_{2 \times 2}
\end{array}\right]^{T} ; \\
& C=\left[\begin{array}{ll}
I & 0_{2 \times 2}
\end{array}\right] ; D=\left[M / L_{s}(1-\sigma) \quad \sigma M / L_{s}(\sigma-1)\right] ; C_{1}=\left[\begin{array}{ll}
0_{2 \times 2} & I
\end{array}\right] ; \\
& A_{11}=-\left(R_{r}(1-\sigma) / \sigma L_{r}+R_{s} / \sigma L_{s}\right) I ; A_{12}=\left(R_{r} / \varepsilon L_{r}\right) I ; \varepsilon=\sigma L_{r} L_{s} / M \\
& A_{21}=\left(M R_{r} / L_{r}\right) I ; A_{22}=\left(-R_{r} / L_{r}\right) I ; A_{\omega 1}=-(1 / \varepsilon) A_{\omega 2}=-(1 / \varepsilon) J ; \\
& B_{1}=\left(1 / \sigma L_{s}\right) I ; I=\left[\begin{array}{ll}
1 & 0 \\
0 & 1
\end{array}\right] ; J=\left[\begin{array}{cc}
0 & -1 \\
1 & 0
\end{array}\right] \text {. } \\
& R_{s}, R_{r} \quad: \text { Stator and Rotor resistance } \\
& L_{s}, L_{r} \quad \text { : Stator and Rotor inductance } \\
& \text { M : Mutual inductance } \\
& \lambda_{s}, \lambda_{r} \quad: \text { Space vector of stator and rotor flux } \\
& i_{s} \quad: \text { Space vector of the stator currents } \\
& \sigma=1-\left(M^{2} / L_{r} L_{s}\right) \quad \text { : Total leakage factor } \\
& \omega_{r} \quad: \text { Angular rotor speed } \\
& p \quad \text { : Number of pole pairs }
\end{aligned}
$$

Equation (4) defines the electromagnetic torque in the stator reference frame.

$$
C e=p\left(3 M / 2 L_{r}\right)\left(\lambda_{r \alpha} i_{s \beta}-\lambda_{r \beta} i_{s \alpha}\right)
$$

\section{The adaptive Flux Observer}

To reconstruct the state variables and to estimate the mechanical speed of the induction machine, a full-order observer is proposed and expressed in its simplest form as shown in the differential equation (5). The observer gain $\boldsymbol{H}$ appears to be obvious. The symbol ${ }^{\wedge}$ above a symbol denotes an estimate value of a parameter or a state variable. 


$$
\hat{\dot{x}}=\left(\hat{A}+\hat{\omega}_{r} A_{\omega}\right) \hat{x}+\hat{B} v_{s}+H\left(\hat{i}_{s}-i_{s}\right)
$$

Where $\hat{A}=A+\Delta A, \hat{B}=B+\Delta B$ and $\hat{C}=C+\Delta C$

In this article, we focus only on the resistive uncertainty. The estimation error $e=x-\hat{x}$ is defined as the difference between real and estimated vectors. The dynamic of estimation error of the rotor flux is described by the following equation (6)

$$
\dot{e}=\left(A+H C+\omega_{r} A_{\omega}\right) e+\Delta \omega_{r} A_{\omega} \hat{x}+\Delta R_{s} A_{R s} \hat{x}
$$

Where

$$
\Delta \omega_{r}=\hat{\omega}_{r}-\omega_{r}, \Delta A=\left(\hat{R}_{s}-R_{s}\right) A_{R s}=\Delta R_{s} A_{R s} \text { and } A_{R s}=\left[\begin{array}{cc}
-\left(1 / \sigma L_{s}\right) I & 0_{2 \times 2} \\
0_{2 \times 2} & 0_{2 \times 2}
\end{array}\right]
$$

To ensure the asymptotic stability of the state estimation error, we consider the following quadratic Lyapunov function

$$
V\left(e, \Delta \omega_{r}, \Delta R_{s}\right)=e^{T} P e+\left(2 \Delta \omega_{r}^{2} / \mu_{1}\right)+\left(2 \Delta R_{s}^{2} / \mu_{2}\right)
$$

Where $P$ is a positive-definite symmetric matrix, $\mu_{1}$ and $\mu_{2}$ two positive design constants.

The time derivative of $V$ is:

$$
\dot{V}\left(e, \Delta \omega_{r}, \Delta R_{s}\right)=\dot{e}^{T} P e+e^{T} P \dot{e}+\frac{2}{\mu_{1}}\left(\Delta \omega_{r}\right)\left(\frac{d \Delta \omega_{r}}{d t}\right)+\frac{2}{\mu_{2}}\left(\Delta R_{s}\right) \frac{d \Delta R_{s}}{d t}
$$

After some calculation, equation (8) becomes

$$
\dot{V}\left(e, \Delta \omega_{r}, \Delta R_{s}\right)=e^{T}\left(\left(A+H C+\omega_{r} A_{\omega}\right)^{T} P+P\left(A+H C+\omega_{r} A_{\omega}\right)\right) e+V_{1}+V_{2}
$$

Where $V_{1}$ and $V_{2}$ are given by the following equations

$$
\begin{aligned}
& V_{1}=\Delta \omega_{r}\left(\left(\hat{x}^{T} A_{\omega}^{T} P e+e^{T} P A_{\omega} \hat{x}\right)+\frac{2}{\mu_{1}}\left(\frac{d\left(\hat{\omega}_{r}-\omega_{r}\right)}{d t}\right)\right) \\
& V_{1}=\Delta R_{s}\left(\left(\hat{x}^{T} A_{R s}^{T} P e+e^{T} P A_{R s} \hat{x}\right)+\frac{2}{\mu_{2}} \frac{d \Delta\left(\hat{R}_{s}-R_{s}\right)}{d t}\right)
\end{aligned}
$$

We consider the variation dynamic of the speed as slower than the error estimation dynamic on the mechanical speed $\left(\dot{\omega}_{r} \approx 0\right)$. The same conditions apply to the dynamic of stator resistance variation and its error estimation dynamic $\left(\dot{R}_{s} \approx 0\right)$. 
By nullifying the sum of $V_{1}$ and $V_{2}$, the relationship between the state error estimation and the dynamics of both speed and stator resistance estimation can be expressed as follows

$$
\begin{aligned}
& \frac{2}{\mu_{1}} \frac{d \hat{\omega}_{r}}{d t}=-\hat{x}^{T} A_{\omega}^{T} P e-e^{T} P A_{\omega} \hat{x} \\
& \frac{2}{\mu_{2}} \frac{d \hat{R}_{s}}{d t}=-\hat{x}^{T} A_{R s}^{T} P e-e^{T} P A_{R s} \hat{x}
\end{aligned}
$$

The first and second terms on the right-hand side of both equations (12) and (13) are scalars; the adaptive law of estimation of the rotor speed and stator resistance can be set in the following equation

$$
\left\{\begin{array}{l}
\frac{d \hat{\omega}_{r}}{d t}=-\mu_{1} e^{T} P A_{\omega} \hat{x} \\
\frac{d \hat{R}_{s}}{d t}=-\mu_{2} e^{T} P A_{R s} \hat{x}
\end{array}\right.
$$

If (14) holds and the gain matrix, $H$, is set in order that the time derivative of Lyapunov equation (9) is nonpositive, this means that the estimation error converges to zero and the observer tracks the real system. In the proposed solution, a PI regulator is used instead of the integral controller (14) to improve the performances of the speed and stator resistance estimators. The adaptation lows of the rotor speed and stator resistance are defined respectively by following equations (15) and (16)

$$
\begin{aligned}
& \hat{\omega}_{r}=K_{p v}\left(e^{T} P A_{\omega} \hat{x}\right)+K_{i v} \int\left(e^{T} P A_{\omega} \hat{x}\right) d t \\
& \hat{R}_{s}=K_{p R s}\left(e^{T} P A_{R s} \hat{x}\right)+K_{i R s} \int\left(e^{T} P A_{R s} \hat{x}\right) d t
\end{aligned}
$$

Where $K_{p v}, K_{i v}, K_{p R s}$ and $K_{i R s}$ are positive design constants

Based on the simplified thermic model of induction machine, and supposing that rotor and stator coils have almost the same temperature, an adaptive mechanism of rotor resistance will be described as follows

$$
\hat{R}_{r}=R_{r}\left(1+\left(\alpha_{R r} / \alpha_{R s}\right)\left(\left(\hat{R}_{s} / R_{s}\right)-1\right)\right)
$$

$\alpha_{\mathrm{Rs}}:$ Temperature coefficient of stator resistance.

$\alpha_{\mathrm{Rr}}$ : Temperature coefficient of rotor resistance. 


\section{Observer Gain Calculation: Pole Placement in LMI Region}

To enhance the dynamic behavior of the proposed flux observer, a robust pole placement algorithm is proposed. The proposed solution uses LMI (Linear Matrix Inequalities) technique. It is suggested to ensure the matrix $\left(\mathrm{A}+\omega_{\mathrm{r}} \mathrm{A}_{\omega}+\mathrm{HC}\right)$ pole placement in specific LMI-regions. The latter is defined by the intersection between a circle centered at center $(0,0)$ with radius $(r)$ and the left half plan limited by a vertical line with the abscissa $(-h)$ where $h$ is positive constant (Figure 1). According to [14] and [15], the LMI formulation of the proposed set up is given by the following equation

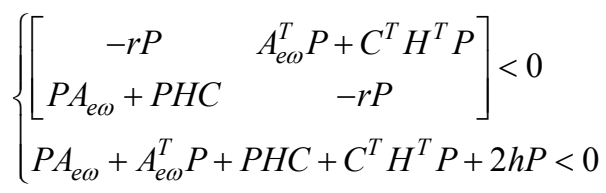

With

$$
P=P^{T}>0 \text { And } A_{e \omega}=A+\omega_{r} A_{\omega}
$$

The bilinear matrix inequality (BMI) (18) can be transformed into LMIs with a change of variables $R=P H$ as follows:

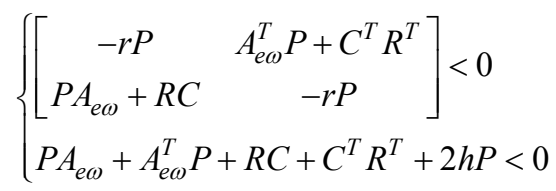

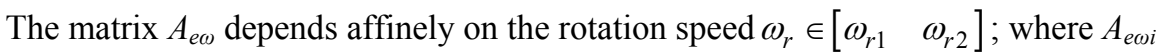
denotes the parameter values of $A_{e \omega}$ at the vertices $\omega_{r i}$ of the parameter polytope. According [9] it is then possible to obtain the observer gain $\boldsymbol{H}$ if and only if there exist real positive matrices $P=P^{T}, R_{1}$ and $R_{2}$ simultaneously satisfy the four following matrices inequalities:

$$
\left\{\begin{array}{cc}
-r P & A_{e \omega i}^{T} P+C^{T} R_{i}^{T} \\
P A_{e \omega i}+R_{i} C & -r P
\end{array}\right]<0 \quad i \in\{1,2\}
$$

The decision variables $P, R_{1}$ and $R_{2}$ can be synthetized numerically under LMI constraints of (20) by using the LMI Control Toolbox of Matlab. As a result, the observer sub-gain $H_{i}$ can be calculated by the following equation

$$
H_{i}=P^{-1} R_{i} \quad i \in\{1,2\}
$$


The observer gain $H$ for a given $\omega_{r} \in\left[\begin{array}{ll}\omega_{r 1} & \omega_{r 2}\end{array}\right]$ can be obtained by the interpolation between the two sub-gains $H_{1}$ and $H_{2}$, as given in the following equation

$$
H\left(\omega_{r}\right)=\frac{H_{1}\left(\omega_{r 2}-\omega_{r}\right)+H_{2}\left(\omega_{r}-\omega_{r 1}\right)}{\omega_{r 2}-\omega_{r 1}}
$$

Finally, the block diagram of the proposed Adaptive state observer of induction machine is shown in Figure 2.

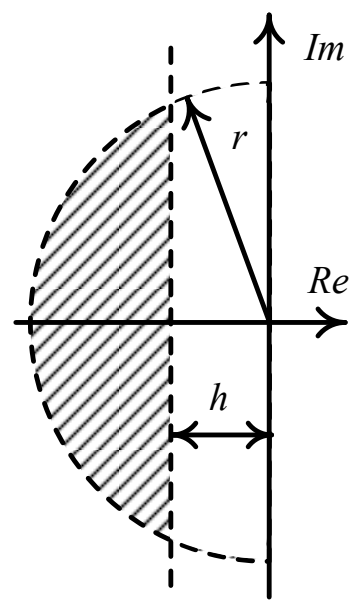

Figure 1

Proposed region

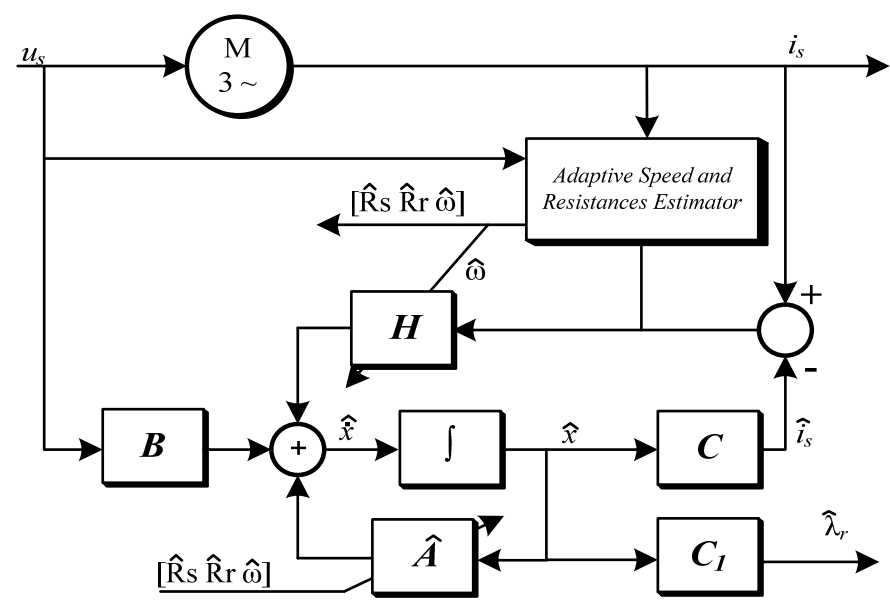

Figure 2

Adaptive state observer of induction machine 


\section{Model-based Efficiency Optimization}

For maintenance reasons, some users prefer the use of electric motors of the same size. Almost half of the electric under-loaded engines operate at less than $40 \%$ of their rated loads [16]. This requires a revision of the strategy control in order to optimize the electrical energy losses. An energy analysis shows that the iron and copper losses represent over $80 \%$ of all losses in an induction motor [17]. To ensure the minimization of energy losses, in [18] we have proposed an adaptive flux control based on the research of optimal flux which corresponds to an operating speed and a load torque (23).

$\lambda_{r d}=M \sqrt[4]{\frac{R_{q}}{R_{d}}} \sqrt{k C e}$

Where

$$
\begin{aligned}
& R_{d}=R_{s}+\left(R_{s}+1\right)\left(\omega_{s} L_{s}\right)^{2} / R_{c} \\
& R_{q}=R_{s}+\left(R_{s} R_{c}+1\right)+\left(\left(\omega_{s} L_{s} \sigma\right)^{2} / R_{c}\right)+R_{r}\left(M / L_{r}\right)^{2} \\
& k=\left(2 L_{r}\right) /\left(3 p M^{2}\right)
\end{aligned}
$$

\section{Results}

To verify the proposed solution, a discrete Simulink model in Matlab ${ }^{\circledR}$ is built based on the control block diagram shown in Figure 3. The parameters of induction motor are shown in Table 1 . The electric power devices including the voltage source inverter, the three-phase induction motor are emulated by Powergui. The adaptive observer and the vector control are programmed with a 10 $\mu$ s sample time. Figure 4 shows the system response to a step speed (500 rpm) under a load torque of $20 \mathrm{Nm}$, the motor takes $50 \mathrm{~ms}$ to reach its steady state. Figure 5 shows the developed electromagnetic torque during the starting phase as well as the stationary phase. The output signal of speed estimator block is used as a feedback for the speed closed loop regulation based on an Anti-Windup PI controller. To verify disturbance rejection on speed control, the load torque is increased by $50 \%$ at $\mathrm{t}=1.5 \mathrm{~s}$ (Figure 5 ). The proposed solution shows a good performance on the speed track (Figure 4), and disturbance rejection in the steadystate. Indeed, the estimated speed converges correctly towards the actual speed.

The three-phase inverter feeds the induction machine based on the control algorithm. In the startup phase, the control system ensures the magnetization of induction motor based on a specific magnetization algorithm. When the rotor flux 
reaches the minimum level, the control system switches to the DFOC algorithm. The first transition lasts $10 \mathrm{~ms}$; the second $240 \mathrm{~ms}$, as illustrated in Figure 6 .

The output signal of the proposed rotor flux observer is re-injected into the input of rotor flux regulation block based on PI controller. The optimal rotor flux magnitude is computed by the Energy Optimization Algorithm block (EOA). At $\mathrm{t}=1 \mathrm{~s}$, the drive system switches from a classical DFOC to a DFOC under optimal rotor flux; Figure 6 shows that the magnitude of reference rotor flux has decreased to $84 \%$ of its rated value. Figure 6 also shows the convergence of the estimated rotor flux to the actual value; a good tracking of the reference is successfully guaranteed by the controller. Due to the sensitivity of the EOA to the stator and rotor resistance variation, the estimator of stator and rotor resistances provides the actual value to the optimization algorithm. To verify the performance of the parameters' tracking system, the actual values of stator and rotor resistances are increased by $20 \%$. Figure 7 and Figure 8 show that the estimated values of rotor and stator resistance converge respectively to their real values.

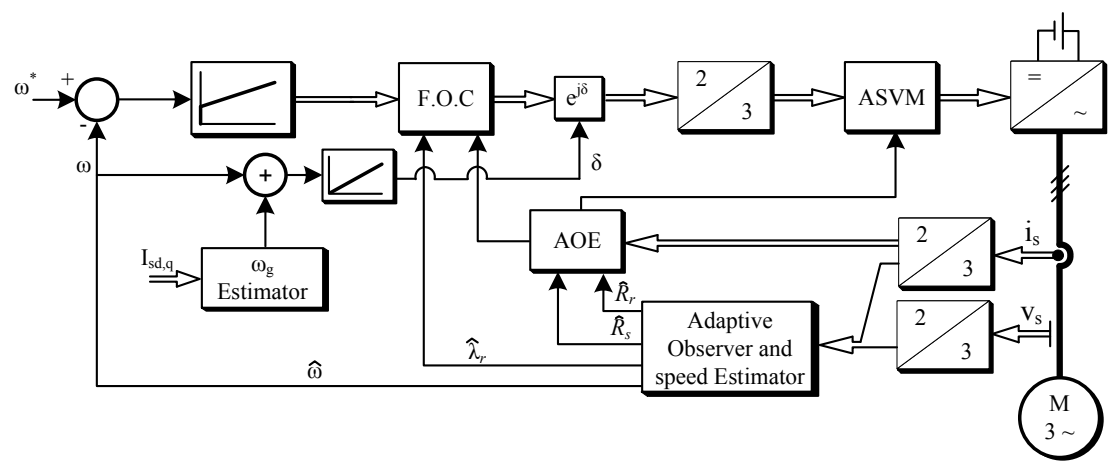

Figure 3

Block diagram of a speed Sensorless control system based on adaptive observer

(AOE: Energy Optimization Algorithm)

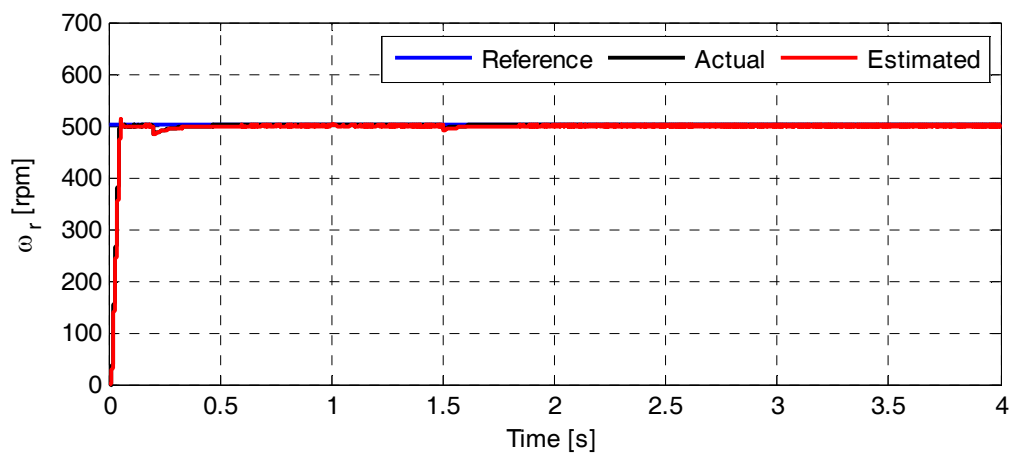

Figure 4

Simulated speed using the proposed speed adaptive scheme 


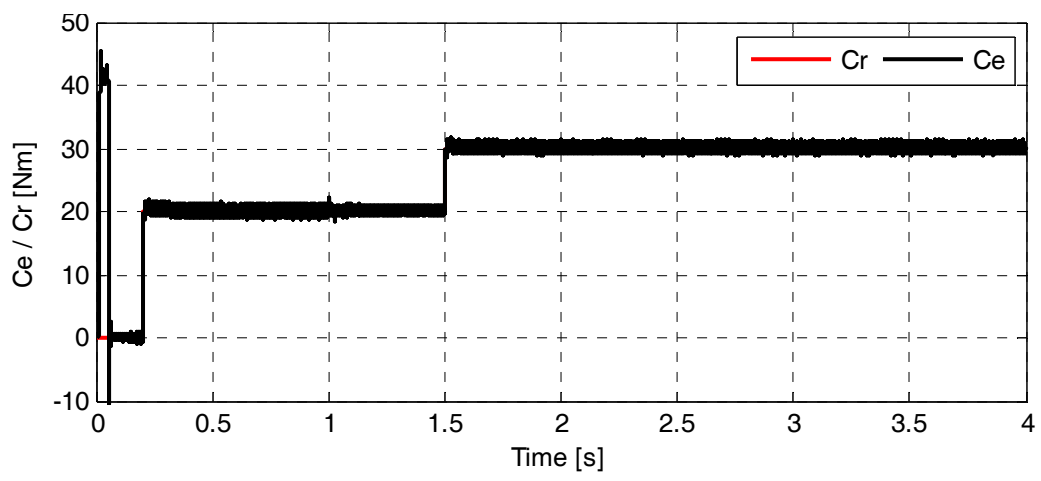

Figure 5

Torque response for step varying of load torque

(Cr: load torque, Ce: electromagnetic torque)

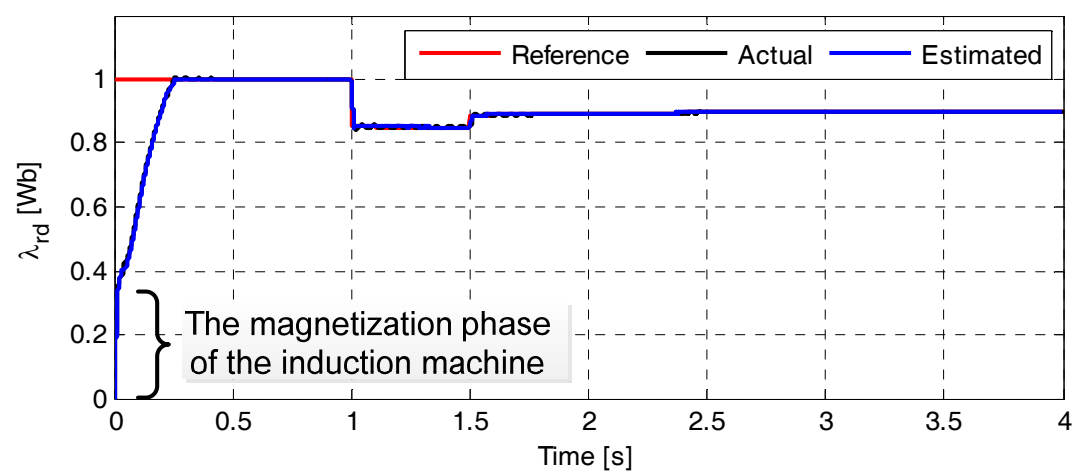

Figure 6

The curve of real and estimated rotor flux

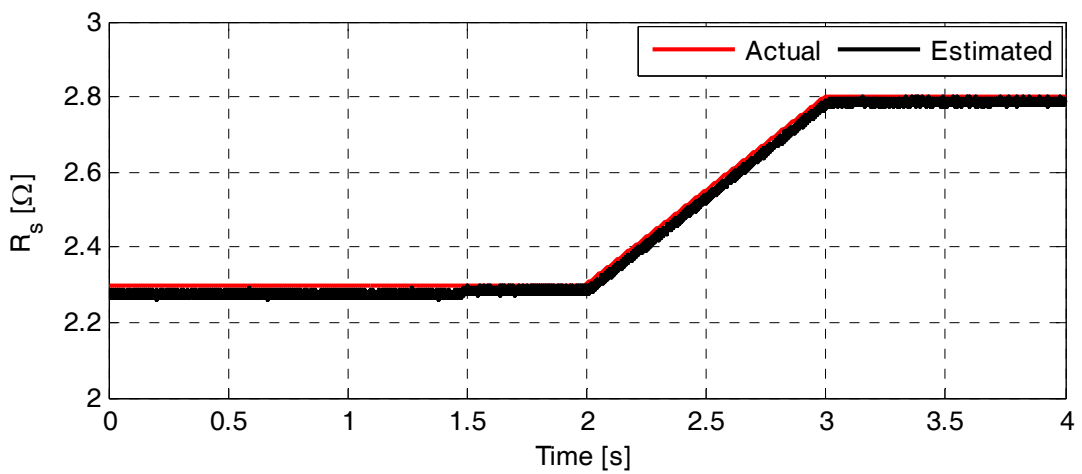

Figure 7

The curve of the stator resistance variation 


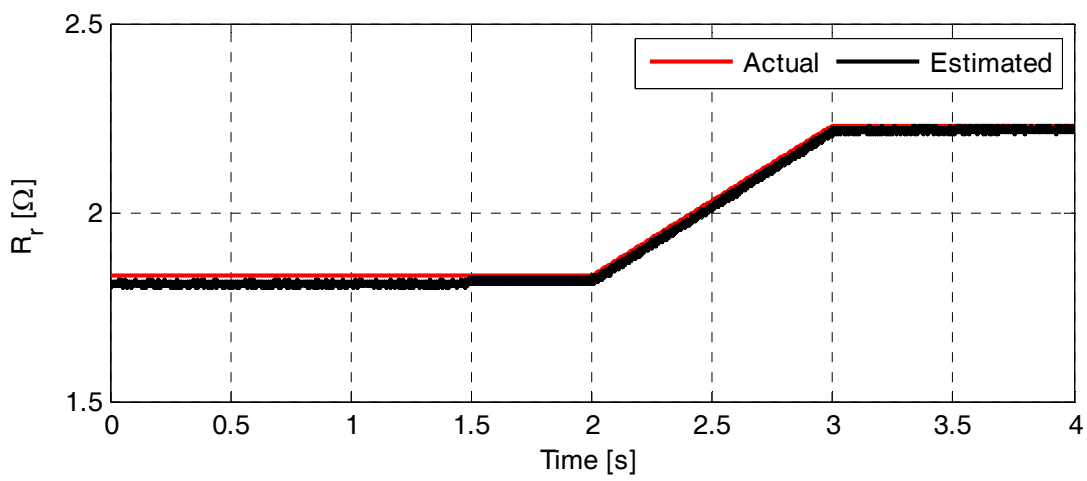

Figure 8

The curve of the rotor resistance variation

Table 1

Induction machine parameters

\begin{tabular}{ccc}
\hline \hline Symbol & Quantity & Rating values \\
\hline$R_{s}$ & Stator resistance & $2.3 \Omega$ \\
$R_{r}$ & Rotor resistance & $1.83 \Omega$ \\
$L_{s}$ & Stator inductance & $0.261 \mathrm{H}$ \\
$L_{r}$ & Rotor inductance & $0.261 \mathrm{H}$ \\
$M$ & Mutual inductance & $0.245 \mathrm{H}$ \\
$\sigma$ & Leakage factor & 0.134 \\
$j m$ & Moment of inertia & $0.03 \mathrm{Kgm}^{2}$ \\
$f$ & Friction coefficient & 0.001 \\
$U_{n}$ & Rated voltage & $380 \mathrm{~V}$ \\
$I_{n}$ & Rated current & $15.1 \mathrm{~A}$ \\
$P_{n}$ & Rated power & $7 \mathrm{KW}$ \\
$p$ & Number of pole pair & - \\
\hline \hline
\end{tabular}

\section{Conclusion}

In this paper, a new Sensorless induction machine drive has been proposed and tested with simulation in the Matlab/Simulink environment. The proposed concept is based on DFOC and a robust flux observer. The observer gain is deduced from Lyapunov theory. To enhance the dynamic and static performances of the proposed observer, the pole placement technique has been used. The observer gain is obtained from solving linear matrix inequalities by using the LMI Toolbox of MATLAB $^{\mathbb{R}}$. Furthermore, the tracking of the actual value of rotor speed as well as stator and rotor resistances is ensured by a PI adaptive law deduced from Lyapunov theory. Along with the DFOC algorithm, an optimization strategy of the energy losses of the induction machine has been introduced.The simulation results show the high static and dynamic perfermances. 


\section{Acknowledgement}

The authors would like to thank the anonymous reviewers for their helpful comments and suggestions to improve the original manuscript.

\section{References}

[1] F. Blaschke, "The Principle of Field-Orientation as Applied to the New 'Transvector' Closed Loop Control System for Rotating-Field Machines,' Siemens-Review, Vol. 34, No. 5, pp. 217-220, 1972

[2] T. Jebali, M. Jemli, M. Boussak, M. Gossa, M. B. Kamoun, "Dspace-based Experimental Results of Indirect Field oriented Control (IFOC) PWM VSI Fed Induction Motor," in IEEE International Conference on Industrial Technology, Hammamet, Tunisia, 2004, Vol. 2, pp. 569-573

[3] A. Laoufi, A. Hazzab, I. K. Bousserhane, M. Rahli, "Direct Field-oriented Control using Backstepping Technique for Induction Motor Speed Control," in Information and Communication Technologies. $2^{\text {nd }}$, Damascus, Syria, 2006, Vol. 1, pp. 1422-1427

[4] B. B. S, V. A. M, "Speed-Sensorless, Adjustable-Speed Induction Motor Drive Based on dc Link Measurement," International Journal of Physical Sciences, Vol. 4, No. 4, pp. 221-232, Apr. 2009

[5] R. Sadouni, A. Meroufel, "Indirect Rotor Field-oriented Control (IRFOC) of a Dual Star Induction Machine (DSIM) Using a Fuzzy Controller," Acta Polytechnica Hungarica, Vol. 9, No. 4, pp. 117-192, 2012

[6] H. Madadi Kojabadi, L. Chang, "Model Reference Adaptive System Pseudoreduced-Order Flux Observer for Very Low Speed and Zero Speed Estimation in Sensorless Induction Motor Drives," in IEEE $33^{\text {rd }}$ Annual Power Electronics Specialists Conference : conference proceedings, Queensland, Australia, 2002, Vol. 1, pp. 301-305

[7] S. Iosif, P. Octavian, F. Ioan, C. Vasar, "Above Flux Estimation Issues in Induction Generators with Application at Energy Conversion Systems," Acta Polytechnica Hungarica, Vol. 3, No. 3, pp. 137-148, 2006

[8] F. R. Salmasi, T. A. Najafabadi, P. Jabehdar-Maralani, "An Adaptive Flux Observer with Online Estimation of DC-Link Voltage and Rotor Resistance for VSI-based Induction Motors," IEEE Transactions on Power Electronics, Vol. 25, No. 5, pp. 1310-1319, 2010

[9] M. B. B. Sharifian, N. Rostami, H. Hatami, "Sensorless Control of IMbased on Full-Order Luenberger Observer," in The $9^{\text {th }}$ International Power and Energy Conference, Singapore, 2010, pp. 567-571

[10] C. Caruana, G. M. Asher, M. Sumner, "Performance of HF Signal Injection Techniques for Zero-Low-Frequency Vector Control of Induction Machines under Sensorless Conditions," IEEE Transactions on Industrial Electronics," Vol. 53, No. 1, pp. 225-238, Feb. 2005 
[11] R. Raute, C. Caruana, C. S. Staines, J. Cilia, N. Teske, M. Sumner, G. M. Asher, "A Review of Sensorless Control in Induction Machines Using hf Injection, Test Vectors and PWM Harmonics," in $2^{\text {nd }}$ IEEE International Symposium on Sensorless Control for Electrical Drives, Birmingham, UK, 2011, pp. 47-55

[12] M. Barut, R. Demir, E. Zerdali, R. Inan, "Real-Time Implementation of Bi Input-Extended Kalman Filter-based Estimator for Speed-Sensorless Control of Induction Motors," IEEE Transactions on Industrial Electronics, Vol. 59, No. 11, pp. 4197-4206, Nov. 2012

[13] S. Wu, Y. Li, Z. Zheng, "Speed Sensorless Vector Control of Induction Motor Based on Full-Order Flux Observer," in CES/IEEE $5^{\text {th }}$ International Power Electronics and Motion Control Conference : Conference Proceedings, Shanghai, China, 2006, Vol. 3, pp. 1-4

[14] M. Chilali, P. Gahinet, P. Apkarian, "Robust Pole Placement in LMI Regions," IEEE Transactions on Automatic Control, Vol. 44, No. 12, pp. 2257-2270, Dec. 1999

[15] M. Chilali, P. Gahinet, "Hळ Design with Pole Placement Constraints: an LMI Approach,” IEEE Transactions on Automatic Control, Vol. 41, No. 3, pp. 358-367, Mar. 1996

[16] R. N. Hasanah, "A Contribution to Energy Saving in Induction Motors," Ph.D, EPFL, LAI, Faculté des sciences et techniques de l'ingénieur, Lausanne, 2005

[17] R. Razali, A. N Abdalla, G. Ruzlaini, C. Venkataseshaiah, "Improving Squirrel Cage Induction Motor Efficiency: Technical Review," International Journal of the Physical Sciences, Vol. 7, No. 8, pp. 1129-1140, Feb. 2012

[18] F. Farhani, A. Zaafouri, "On-Line Tuning of Efficiency Optimization of Induction Machine Drive," in $16^{\text {th }}$ IEEE Mediterranean Electrotechnical Conference (MELECON), Hammamet, Tunisia, 2012, pp. 1137-1140 